
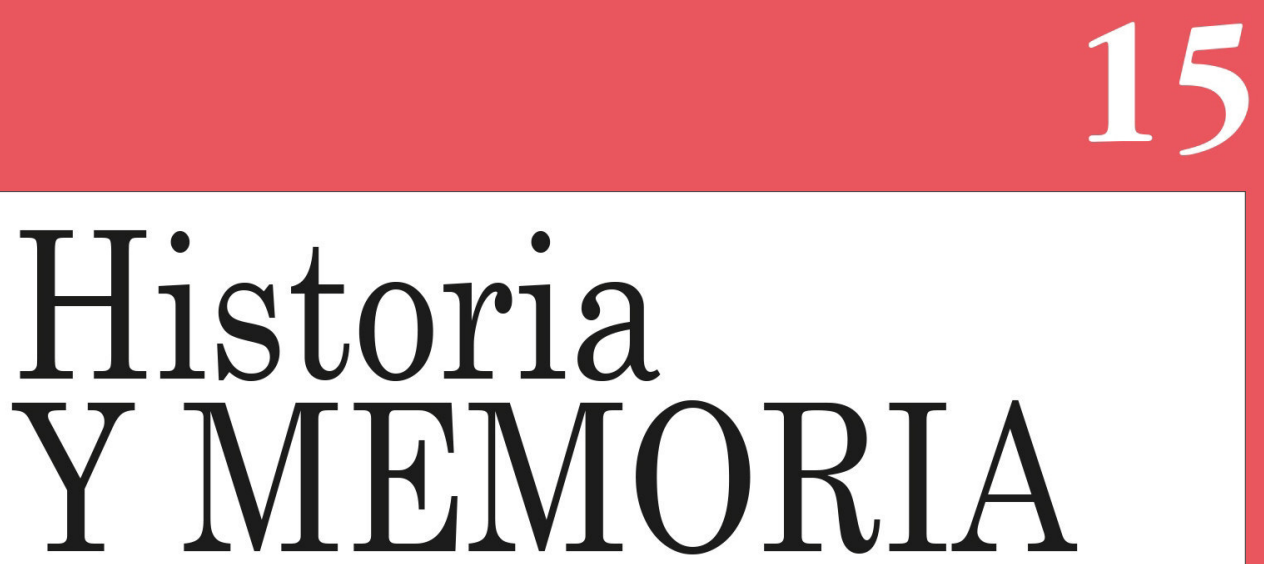

ISSN: 2027-5137 Julio - Diciembre, Año 2017 - Tunja, Colombia

Presentación: Historia, memoria y patrimonio histórico colonial en Colombia

https://doi.org/10.19053/20275137.n15.2017.6578

Antonio E. de Pedro

orcid.org/0000-0001-5513-1057

Páginas: 11-14

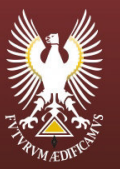




\title{
Presentación: Historia, memoria y patrimonio histórico colonial en Colombia
}

\author{
Antonio E. de Pedro ${ }^{1}$ \\ Universidad Pedagógica y Tecnológica de Colombia
}

https://doi.org/10.19053/20275137.n15.2017.6578

En este nuevo número de la revista Historia Y MEMORIA ofrecemos un pequeño panorama de publicaciones preocupadas por asuntos relacionados con el patrimonio histórico colonial en América Latina.

Empezamos nuestro número con una investigación en relación con «El Museo arqueológico de Pasca: una hipótesis sobre su origen» de José Abelardo Díaz Jaramillo, investigador de la Corporación Universitaria del Meta, Colombia. El texto indaga en relación con el origen del Museo Arqueológico de Pasca (MAP); museo creado por el párroco Jaime Hincapié Santamaría, con la intención de fortalecer los vínculos entre la comunidad y la parroquia, en un contexto local marcado

1 Doctor en Historia en Filosofía y Letras, especialidad Historia del Arte, por la Universidad Autónoma de Madrid, 1991. Docente de Tiempo Completo del Doctorado y Maestría en Historia de la Universidad Pedagógica y Tecnológica de Colombia. Ha sido profesor investigador de universidades de España y México. Ha estado vinculado a diversos proyectos de investigación internacional desarrollados por el Departamento de Historia de la Ciencia del Instituto de Estudios Históricos de Madrid, perteneciente al Consejo Superior de Investigaciones Científicas de España (CSIC). Ha sido miembro del Sistema Nacional de Investigadores de México (CONACYT), y, actualmente, del Sistema Nacional de Investigadores de Colombia (COLCIENCIAS). Sus últimas publicaciones son: (Coeditor) (2015). Cómo ver Cómo. Textos sobre la cultura Visual Latinoamericana. Editorial Foc, Barcelona (Libro Electrónico); (2016) (Coordinador) «El Arte Latinoamericano durante la Guerra Fría: Figurativos vs Abstractos». Monográfico de Nuevas Lecturas de Historia, 36, (UPTC); «Identidad y Nación en exhibición. La ciudad de México, siglos XIX y XX». Revista INDIANA, n 31, Ibero-Amerikanisches Institut Preussischer Kulturbesitz, Berlín, 2014. Actualmente es presidente de la Red de Estudios Visuales Latinoamericanos (REVLAT) www.revlat.com. $ه$ labra1957@ gmail.com (iD) orcid.org/0000-0001-5513-1057. 
por conflictos agrarios de larga duración. La particularidad de este museo local, y que es parte importante del argumento de esta investigación, es que la iniciativa del párroco no estuvo marcada por un discurso religioso, sino por la reivindicación de exaltación de un pasado indígena local y regional.

La investigadora de la Universidad Nacional de Colombia, Laura Liliana Vargas Murcia, nos ofrece recientes investigaciones sobre la labor de pintores del periodo local en la ciudad de Tunja, Boyacá, Colombia. "Pintores en el esplendor de Tunja: nombres de artífices para salir del anonimato (siglos XVI y XVII)» es un texto de indudable que se centra en la búsqueda de información a partir de las investigaciones de Magdalena Corradine Mora sobre los habitantes de la ciudad de Tunja en las primeras décadas del siglo XVII, y la investigación de documentación en el Archivo Histórico Regional de Boyacá. La intención de la autora, es llamar la atención sobre estos artistas locales, que permita emprender futuros trabajos sobre ellos y sus obras.

El profesor e investigador Luis Rubén Pérez Pinzón de la Universidad Autónoma de Bucaramanga, Colombia, nos ofrece un texto sobre un proceso de recuperación de la memoria histórica, con la intención de desterrar tergiversaciones: «Tergiversaciones sobre la batalla de Cachirí y el restablecimiento del régimen virreinal neogranadino (1816)». El texto describe cómo han variado las explicaciones entre la historia oficial, la memoria popular y el patrimonio monumental de las élites regionales acerca de la batalla que decidió el triunfo del ejército expedicionario de español en el proceso de independencia colombiano. Se analizaron los discursos históricos que caracterizan la versión oficial, contrastándolos con las representaciones históricas regionales y nacionales, y destacando vacíos y anacronismos históricos que han determinado la memoria popular de dicho hecho histórico.

Finalmente, nuestro pequeño Dossier recoge un estudio sobre la población afrocolombiana en el texto: «Manifestaciones artísticas y culturales afrocolombianas. Una aproximación 
al caso de Girardota (Antioquia)». Los profesores de la Universidad Nacional de Colombia, sede Medellín, América Larraín González y Pedro José Madrid Garcés se acercan al fenómeno de la participación de este grupo cultural y social, en el ámbito municipal, destacando que hay un lazo indisociable entre la participación de la comunidad en escenarios políticos y de organización comunitaria; además, del carácter étnico que se atribuye a sus manifestaciones artísticas y culturales.

Como es tradición en nuestra revista, incluimos en la Zona Libre una serie de textos que procuren dialogar con los textos incluidos en nuestro Dossier. Iniciamos con un texto sobre mundo colonial americano: «Evangelización y occidentalización en la frontera sur del Reino de Chile. Los Franciscanos del Colegio de Misiones de Chillán, s. XVIII» de Cristián Leal Pino (Universidad del Bío Bío, Chile) y Andrés Quitral Manosalva (Universidad Andrés Bello, Chile), que se adentra en los procesos de evangelización tardía del siglo XVIII. Seguidamente, ofrecemos un estudio sobre migración española a América en los primeros años del siglo XX: «Migración española hacia América desde la perspectiva de la Cartilla del Emigrante (1910)» del investigador Martín Pérez Acevedo (Instituto de Investigaciones Históricas UMSNHMéxico). Nuestro tercer texto en esta sección, está dedicado al estudio de caso sobre procesos de industrialización en la región de Boyacá, Colombia: «El papel del Estado colombiano en la conformación del sector siderúrgico de Boyacá. 1938-1980», de los profesores colombianos, Patricia Carolina Barreto (Universidad Pedagógica y Tecnológica de Colombia, Boyacá, Colombia) y Juan Carlos Jurado Jurado (Universidad EAFIT, Medellín, Colombia). Continuamos, con la colaboración del profesor mexicano Francisco A. García Naranjo, (Universidad Michoacana de San Nicolás de Hidalgo, México) nos propone en su texto: «El Gobernador de Michoacán y el conflicto universitario de 1949. La mirada de Nemesio García Naranjo»; un análisis de los escritos del periodista Nemesio García Naranjo, en relación con los sucesos desatados entre el 28 de julio y el 26 de agosto de 1949 entre los estudiantes y autoridades de la Universidad Michoacana y el Gobernador del Estado. Para finalizar, la Zona Libre, con el texto del 
profesor Liborio González Cepeda (Universidad Pedagógica y Tecnológica de Colombia, Boyacá), sobre las consecuencia de la Guerra Fría en Colombia, y la necesidad de establecer una periodicidad sobre dicho fenómeno: «La guerra fría en Colombia. Una periodización necesaria».

Se incluyen, igualmente, en este número, la sección Reseñas y Debates. En ella, el lector encontrará un conversatorio con el profesor e investigador del arte español el Dr. David Moriente, sobre métodos de enseñanza de la Historia no convencionales, y dos reseñas de obras publicadas realizadas por Julián Andrei Velasco Pedraza y María Teresa Cortés Zavala.

Les deseamos a todas y todos buena lectura y mejor reflexión. 